\title{
PERSPECTIVAS E PRÁTICAS DA APRENDIZAGEM ORGANIZACIONAL NO AMBIENTE DO TRABALHO EM UMA ONG
}

\author{
Luiz Fernando Moreira ${ }^{1}$ \\ Universidade de Caxias do Sul \\ lfmoreira@ucs.br
}

Carlos Eduardo Schlindwein ${ }^{2}$

Universidade de Caxias do Sul eduschlindwein@hotmail.com

\author{
Uiliam Hahn Biegelmeyer ${ }^{3}$ \\ Universidade de Caxias do Sul \\ uiliam.hb@terra.com.br
}

\begin{abstract}
Resumo
O objetivo deste artigo é identificar e compreender os processos formais em informais de aprendizagem organizacional dos colaboradores de uma ONG e suas práticas profissionais. A estratégia de pesquisa é qualitativa exploratória de natureza aplicada como técnicas de coleta de dados foi utilizado entrevista semiestruturada, observação não participante e pesquisa documental. Foram entrevistados 9 colaboradores de diferentes formações e setores da ONG. A aprendizado informal, se deu por meio de conversas, experiências em outros projetos, trocas de informação e experiências decorridas de trabalhos anteriores. Quanto aos formatos de aprendizagem formal, acontecem na forma de leitura, treinamentos, reuniões, palestras e projetos.
\end{abstract}

Palavras-chave: Aprendizagem informal. Aprendizagem formal. Organização não governamental.

\section{PROSPECTS AND PRACTICES OF ORGANIZATIONAL LEARNING IN THE WORK ENVIRONMENT IN AN NGO}

\begin{abstract}
The aim of this paper is to identify and understand the formal processes in organizational learning information of NGO employees and their professional practices. An exploratory qualitative research strategy of applied nature, such as data collection techniques, was used semi-structured interview, non-participant observation and documentary research. Nine employees from different NGO backgrounds and sectors were interviewed. Informal learning took place through conversations, experiences in other projects, exchanges of information and experiences arising from previous work. As for formal learning formats, reading training, training, meetings, lectures and projects.
\end{abstract}

Keywords: Informal learning. Formal Learning. Non-governmental organization.

\footnotetext{
${ }^{1}$ Doutorando em Administração na Universidade de Caxias do Sul. Mestre em Administração. Engenheiro de Produção.

${ }^{2}$ Mestre em Administração pela Universidade de Caxias do Sul. Graduação em Administração.

${ }^{3}$ Doutorado e Pós doutorado em Administração na Universidade de Caxias do Sul. Mestrado e Graduação em Administração pela Universidade de Caxias do Sul.
} 


\section{ARTIGO}

INOVAÇÃo

\section{INTRODUÇÃO}

O trabalho na esfera mundial tem sido acertado como um argumento particular de aprendizagem, tanto cognitivo como socialmente, no qual o sujeito desenvolve ininterruptamente a capacidade de aprender e socializar-se (BRANDI; ELKJAER, 2011). Por isso, suas lentes estão focalizadas no que as pessoas aprendem no trabalho, no uso que fazem dessa prática adquirida nas suas atividades laborais diárias e quais os impactos nos colegas e na organização.

A revisão de literatura sobre aprendizagem informal e formal nos locais de trabalho confirma que o tema tem sido metodicamente atestado. Um estudo sobre aprendizagem informal apresentados por segundo Reatto e Godoy (2015), não se revelou expressiva nem em termos numéricos (exclusivamente 21 artigos em periódicos no período 2006-2012) nem conceituais (não se atentando em balizar com clareza o julgamento de aprendizagem informal, seguindo significados comuns e habituais). De acordo com Reatto e Godoy (2015) é aceitável que a aprendizagem se desenvolver no ambiente de trabalho, especialmente, de caráter informal, pois quão intensamente essa aprendizagem advém por meio das ocasiões que estão interligadas nas rotinas e métodos de trabalho habitua aprendizagem informal, há máxima chance de a aprendizagem informal acontecer com aprendizagem informal assiduidade do que a formal.

No que tange a aprendizagem formal são ações, voltadas ao aprimoramento contínuo e adequação constante por parte dos sujeitos nas organizações, são esquematizadas e destacadas em torno de princípios essenciais de aprendizagem, de acordo com a tradição por meios formais sistematizados em volta de acontecimentos ou preceitos instrucionais, especialmente treinamento (ABBAD; BORGES-ANDRADE, 2004). A aprendizagem se torna expressiva, segundo Ausubel e Cols. (1983), caso se situem relações entre o conteúdo da aprendizagem e o repertório atual do sujeito.

De acordo com local delimitado para a pesquisa uma ONG onde será investigado os processos de aprendizagem formal e informa do local de trabalho. No Brasil as ONGs são usadas desde o princípio dos anos de 1990 para indicar as organizações da coletividade civil sem fins lucrativos, criadas e alimentadas especialmente pela participação voluntária tendendo à solução de problemas sociais (SOUR, 1999).

Aí vem a questão desta pesquisa: como ocorre os processos de aprendizagem organizacional no ambiente de trabalho em uma ONG? E tem como por objetivo principal: identificar, delinear e compreender os processos formais em informais de aprendizagem 
organizacional dos colaboradores de uma ONG e o que utilizam para aprender seus afazeres profissionais.

O artigo aqui proposto está organizado da seguinte forma: na primeira seção, a introdução traz a contextualização do campo de estudo de aprendizagem informa e formal, bem como objetivo. Na segunda seção, apresenta-se o referencial teórico baseado nos estudos sobre aprendizagem organizacional, os processos de aprendizagem informal e formal, caracterização do que é uma ONG. A terceira seção a proposta metodológica que orientará a realização da pesquisa de campo. Na quarta seção, apresenta e examina os resultados encontrados no campo e, finalmente, na quinta e última seção são articuladas as considerações finais deste trabalho.

\section{APRENDIZAGEM ORGANIZACIONAL - AO}

As pessoas não familiarizadas com a abordagem teórica do conceito das disciplinas que tem por composição o mundo da administração podem ter determinada dificuldade em aceitar a conexão situada muito apressadamente no aspecto deste artigo; afinal, seria tão óbvia assim a cientificidade das pesquisas em AO?

Shrivastava (1983) distinguiu o desenvolvimento de quatro arranjos teóricos nos estudos de AO: AO como adequação, AO como compartilhamento de pressuposições, AO como ampliação de conhecimento sobre analogias ação-resultado e $\mathrm{AO}$ como efeitos do experimento institucionalizado. A AO como compartilhamento de pressuposições baseia-se nos padrões de March (1995) e de Argyris e Schön (1996), onde as organizações aprendem a partir das pessoas e as pessoas aprendem a partir das organizações, ao assimilar hábitos, metodologias, normas, além de crenças e modelos mentais cognitivos.

Marsick e Watkins (2001) dividem a aprendizagem em três níveis, apresentados no quadro 1.

Quadro 1 - Três níveis de aprendizagem.

\begin{tabular}{|c|l|}
\hline Nível individual & $\begin{array}{l}\text { A aprendizagem é a decorrência das experiências que perpetraram sentido para um } \\
\text { sujeito, ou seja, são reconstruções cognitivas do que foi aprendido com alguns } \\
\text { experimentos tanto os positivas quanto os negativos. }\end{array}$ \\
\hline Nível grupal & $\begin{array}{l}\text { A aprendizagem é a edificação recíproca de novos conhecimentos, contendo a } \\
\text { capacidade para ações colaborativas e concordadas }\end{array}$ \\
\hline Nível organizacional & $\begin{array}{l}\text { Está relacionada o experimento coletivo da organização ou sua competência de } \\
\text { agir de forma coerente e rápida, em retorno às alterações do conjunto ambiental e } \\
\text { à sua estrutura interna, ao próprio tempo extrabarreiras para novas aprendizagens } \\
\text { em um método contínuo. }\end{array}$ \\
\hline
\end{tabular}

Fonte: Adaptado de Marsick e Watkins (2001). 
Quando o foco de verificação do estudo é com afinidade aos tipos de aprendizagem, com o isolamento entre a aprendizagem formal e informal, questões ao mesmo tempo surgem. Conclua-se, que a aprendizagem organizacional apela ao indivíduo e a suas influências mútuas, sejam grupal, intergrupal, organizacional e inter-organizacional, desse modo, em nível interpessoal (ANTONELLO; GODOY, 2010).

\section{APRENDIZAGEM FORMAL E INFORMAL NO AMBIENTE DO TRABALHO EM ONGS}

Os primeiros pilares sobre indagações em aprendizagem informal brotaram na década de 90 segundo os autores Marsick; Watkins e Garrick (2001), os quais pautavam a opinião de aprendizagem com termos como aprendizagem en passant, aprendizagem fortuita e não formal, exemplo social, aprendizagem experiencial, aprendizagem autodirigida, aprendizagem na ação, meditação na ação, meditação crítica, aprendizagem transformativa, conhecimento tácito, aprendizagem centrada e comunidades de prática. De tal maneira que Marsick e Watkins (2001), na bibliografia internacional, quanto Antonello (2011), na bibliografia nacional, alertam que, apesar de todos esses termos permaneçam associados com a aprendizagem formal bem como informal, nem sucessivamente podem ser considerados sinônimos das mesmas.

A pesquisa online realizada pela Sociedade Americana de Treinamento e Desenvolvimento e pelo Instituto para Produtividade Corporativa com 1104 profissionais da área de recursos humanos e de aprendizagem definiu a aprendizagem informal em uma atividade de aprendizagem que não é simplesmente reconhecível como treinamento formal e como apoio para a performance. De modo geral, incide sem um instrutor convencional e é controlada pelo empregado em termos de amplitude, profundidade e tempo. Tende a ser particular, restrita nos objetivos e usada em pequenos grupos (MARSICK; YATES, 2012).

Segundo Marsick, Watkins (1990), a aprendizagem informal é estimada como um subproduto de que aprendizagem formal requer atividades, como por exemplo, a execução de tarefas, o intercâmbio interpessoal, o sentimento da cultura organizacional, a experiência por tentativa e erro, e a própria aprendizagem formal, que pode ser incitada por uma organização ou pode ocorrer apesar da atmosfera não ser exatamente favorável para isto.

No enfoque da Administração, a aprendizagem informal adapta-se bem nos novos desenhos de como as organizações se estruturarem e de serem geridas, além de ter a aptidão de romper o poder do sistema do ensino formal (GARRICK, 1998).

A aprendizagem formal no espaço organizacional, por mais que recorra a atividades de 
aprendizagem intencionalmente arquitetadas e normalmente estimadas pertencentes ao domínio de desenvolvimento de recursos humanos, apresenta em algumas situações, caráter experiencial. Essa atuação de desenvolvimento formal estabelece-se de educação ininterrupta e treinamentos, como por exemplo (DUTRA, 2001.) As organizações contam com múltiplos procedimentos de aprendizagem formal, de acordo com Bednall e Sanders (2017), e estas atuações têm o desígnio de alargar o conhecimento e as aptidões dos funcionários, como workshops e seminários de treinamento

Esta pesquisa orientou-se em seu desenvolvimento metodológico pelo também juízo de Malcon et al. (2003), admitindo que os ambientes e tempos de aprendizagem, cultivados pelos indivíduos e a serem pesquisados, constituiriam aqueles que conservariam a natureza das características da informalidade nas inter-relações que constituem com os ambientes e tempos onde a aprendizagem formal se desenvolve no dia-a-dia dos ambientes de organizações (RACKUS et al., 2019). Segundo Borges-Andrade et al. (2006) a aprendizagem formal ocorre em organizações ou eventos preparados e estruturados (PETERS; ROMERO, 2019).

Para proceder à identificação dos atributos de formalidade e informalidade, Malcolm, Hodkinson e Colley (2003) propuseram que cada experiência de aprendizagem seja analisada de acordo com quatro aspectos: processo, localização e cenário, objetivos e conteúdo. Os exemplos dados pelos autores foram esquematizados no Quadro 2.

Quadro 2 - Atributos de formalidade e informalidade.

\begin{tabular}{|c|c|}
\hline \multicolumn{2}{|c|}{ Atributos da formalidade/informalidade da aprendizagem } \\
\hline Caráter Formal & Caráter informal \\
\hline $\begin{array}{c}\text { Educacionalmente institucionalizados; fechados; } \\
\text { pré-determinados; singulares; reduzidos, } \\
\text { delimitados; estruturados; mediados exclusivamente } \\
\text { por alguém; interação unidirecional }\end{array}$ & $\begin{array}{c}\text { Cotidianamente vivenciados no trabalho, } \\
\text { comunidade, etc; abertos; indeterminados; plurais; } \\
\text { ampliados; extensivos; não estruturados; mediados } \\
\text { de forma compartilhada, colaborativa e cooperativa } \\
\text { pelos funcionários; Intercâmbio em rede }\end{array}$ \\
\hline
\end{tabular}

Fonte: adaptado pelos autores a partir de Malcolm, Hodkinson e Colley (2003).

No quadro 2 foi destacado os processos formais e informais de acordo com os autores Malcolm, Hodkinson e Colley (2003). O uso de alguns outros termos que não o informal ou o formal, Malcolm, Hodkinson e Colley (2003, p. 318) sugerem que

os termos e julgamentos usados sejam continuamente e seriamente sejam desenvolvidos para objetivos particulares e que os autores apontem como e por que estão empregando aprendizagem informal posicionamentos teóricos.

Segundo Touré, Michel e Marty (2017) muitos pesquisadores corroboraram a estima do aprendizado informal no trabalho, contudo são insuficientes os estudos que disponibilizam 
métricas de investigação da efetividade das ações formais de aprendizagem (PETERS; ROMERO, 2019).

Nas organizações não governamentais (ONGs), aprendizagens informais e formais estão implantadas, do ponto de vista formal. Juridicamente, toda ONG é um círculo civil ou uma fundação privada, isto é, elas não têm figura jurídica adequada prevista em legislação; evidentemente, nem toda círculos cíveis ou fundação é uma ONG (Associação Brasileira de organizações não governamental aprendizagem informal (ABONG, 2019). As ONGs caracterizam-se por se consistir em grupos social aprendizagem informal constituídos, com estrutura formal e sem fins lucrativos e por satirizarem de autonomia ampla no exercício de sua função sociopolítica voltada em uma única ação distinta para ações de solidariedade (ABONG, 2019; ANESE; COSTA; COELHO, 2018; RIBEIRO, LUZ, 2010).

Aprendizagem e trabalho eram julgamentos que sempre habituaram ser vistos como independentes, em que o trabalho convinha para a produção de bens para a sobrevivência, enquanto que a aprendizagem se pautava à educação protocolar imprescindível para adentrar no ambiente de trabalho. No entanto, para afrontar o novo fato de que o conhecimento é a solução fundamental de uma organização hoje, o ambiente de trabalho tem recebido a importância como um ambiente importante para prover os indivíduos de uma aprendizagem adequada (BOUD; GARRICK, 1998).

\section{PROCEDIMENTOS METODOLÓGICOS}

Nesta seção, esclarecem-se o tipo de pesquisa, seu enfoque ontológico- epistemológica a técnica de pesquisa com a conjectura do instrumento de coleta de dados, demarcação dos participantes e a estratégia de análise dos dados, a fim de se garantir atribuição em função dos objetivos da investigação.

Ao optar pela técnica qualitativa, o pesquisador parte de um conceito de que o fato é socialmente arquitetado por meio do relacionamento pessoal entre pesquisador e seu objeto de estudo, procurando-se respostas a questões que abarcam métodos a partir dos quais experiências sociais são empregadas, vivenciadas e contraem algum significado. Assim, o papel do pesquisador é capturar significados que permeiam a cultura a partir da ótica daqueles que dela compartilham (GODOY, 2013).

Segundo Godoy (2013), as três premissas basilares dessa noção de se fazer pesquisa em ciências sociais são: (a) os seres humanos agem em direção às coisas a partir das definições que aprendizagem informal acontecimentos têm para eles; (b) os sentidos que os seres humanos 
conferem às coisas derivam das influências sociais que eles nutrem com seus iguais, nativas dos processos interativos que incidem entre as pessoas; (c) esses significados são ajuizados e alterados por um processo interpretativo empregado pela pessoa ao debater com as coisas com as quais ela mantém contato no mundo baseado na experiência.

Flick (2009), elucida que a decorrência dessas três premissas é que as desiguais maneiras pelas quais os indivíduos acolhem de significado os objetos, os acontecimentos e as experiências educam o ponto de partida central para a pesquisa sob este enfoque. No estudo de caso, o pesquisador emprega dados recolhidos em ocasiões distintas, com o uso de variadas fontes de observação. As técnicas basilares da coleta de dados são a observação e a entrevista (GODOY, 2005). Para Yin (2010), a entrevista é uma das fontes para o estudo qualitativo, por prover informação, deve ser focalizada e corresponder a um apurado conjunto de questões de um roteiro semiestruturado.

De natureza aplicada, o nível do estudo foi exploratório, assim trabalhou-se somente com categorias a posteriori. Também, essa escolha é explicada pela modalidade de estudo de caso intrínseco, porque ao pesquisar o caso, houve interesse em apreciar melhor o processo, os resultados, de tal modo a organização com o propósito intrínseco e, não pois que esse caso oferece um problema característico (STAKE, 1995).

\subsection{CAMPO DE DESENVOLVIMENTO DO ESTUDO}

A escolha da Casa Anjos Voluntários foi proposital, por ser uma Organização da Sociedade Civil, que se distingue por proporcionar um Serviço de Convivência e Fortalecimento de Vínculos para Crianças e Adolescentes. Foi constituída em fevereiro de 2003, em uma área de vulnerabilidade social abrangida por 18 bairros da zona oeste de Caxias do Sul (RS). Hoje, são acolhidos 195 crianças e adolescentes, no turno oposto à escola.

A autorização para a realização da pesquisa foi obtida por meio de conversa formal com a Diretora da Casa Anjos Voluntários. Devidamente ciente sobre os desígnios dos pesquisadores em desenvolver o artigo do presente estudo, os entrevistados se inteiraram sobre a natureza da pesquisa; quem seriam os pesquisados e os métodos de aquisição de informações (entrevistas); sem gerar riscos e desconfortos de acordo com a Resolução no . 196/1996 do Conselho Nacional de Saúde, a qual coloca critérios de ética em pesquisa com seres humanos; confidencialidade e benefícios. 


\subsection{COLETA DE DADOS E PERFIL DOS RESPONDENTES}

A coleta de informações usou como instrumento um roteiro para entrevistas semiestruturado, pois a perspectiva é que os pontos de vista dos participantes da pesquisa sejam demonstrados em uma circunstância de entrevista com um planejamento aberto (FLICK, 2009), na qual as informações fossem construídas num processo dialógico entre entrevistado e entrevistador, conforme roteiro de entrevista adaptado de Reatto. D (2014).

A escolha dos entrevistados aconteceu por conveniência, foram entrevistadas 9 pessoas, ou seja, 2 professores de oficina, 4 educadores sociais, 1 coordenador geral, 1 assistente social, 1 coordenadora de projeto. O Quadro 3 caracteriza as pessoas que foram entrevistadas.

Quadro 3 - Dados dos entrevistados.

\begin{tabular}{|c|l|l|l|l|l|}
\hline Entrevistados & \multicolumn{1}{|c|}{ Sexo } & \multicolumn{1}{|c|}{ Cargo } & $\begin{array}{l}\text { Tempo de } \\
\text { casa }\end{array}$ & \multicolumn{1}{|c|}{ Formação } & $\begin{array}{l}\text { Duração da } \\
\text { entrevista }\end{array}$ \\
\hline E1 & Masculino & Professor de oficina & 1 ano & Administração & 20 minutos \\
\hline E2 & Feminino & Educadora Social & 11 meses & $\begin{array}{l}\text { Psicologia } \\
\text { cursando }\end{array}$ & 20 minutos \\
\hline E3 & Masculino & Educador Social & 7 meses & Ed. Física & 20 minutos \\
\hline E4 & Feminino & Educadora Social & 2 anos & $\begin{array}{l}\text { Pedagogia } \\
\text { cursando }\end{array}$ & 17 minutos \\
\hline E5 & Masculino & Educador Social & 3 anos & Serviço Social & 20 minutos \\
\hline E6 & Masculino & Coordenador Geral & 5 anos & Ensino Médio & 17 minutos \\
\hline E7 & Feminino & Assistente Social & 3 anos & Serviço Social & 35 minutos \\
\hline E8 & Masculino & Professor de oficina & 4 anos & Dança & 18 minutos \\
\hline E9 & Feminino & $\begin{array}{l}\text { Coordenadora de } \\
\text { projeto }\end{array}$ & 4 anos & Psicologia & 28 minutos \\
\hline
\end{tabular}

Fonte: Elaborado pelos autores (2019).

As entrevistas geraram três horas e vinte e cinco minutos de áudio, em sua totalidade, fornecendo subsídio para pesquisa.

\subsection{OBSERVAÇÃO NÃO PARTICIPANTE E PESQUISA DOCUMENTAL}

A observação tem papel basilar em pesquisas de abordagem qualitativa. Ela ocorre quando o pesquisador não intervém nas ações que está observando nem na coleta dados e não participa espontaneamente do fato. É imprescindível possuir um roteiro para a observação, a fim de outorgar apoio ao máximo admissível de fatos sobre o tema da pesquisa. As observações podem ser feitas durante as próprias entrevistas efetivadas, em reuniões para o agendamento, em visitas institucionais ou em qualquer outra ocasião em que o pesquisador estiver presente no ambiente a ser pesquisado (DENZIN et al., 2008). 
Pesquisa em documentos bem como anotações foram identificadas e analisadas, para Denzin et al. (2008), essas anotações e documentos são relevantes para registrar ideias e novos elementos descobertos durante as observações do pesquisador. Esta pesquisa utilizou-se técnicas diferentes para a coleta dos dados - entrevista semiestruturada, observação não participante e consulta a relatórios e fontes disponíveis, como site da ONG e a rede social, para dados secundários -, ocasionando sua triangulação.

Para tanto, foi utilizado o software NVivo®, empregando-se para a codificação todo o material coletado durante as entrevistas (sistematizado por meio de áudios e transcrições), fotos, diários de campo (contendo anotações das evidências observadas) e também dados secundários (apresentados por meio de sites da ONG etc mostrado na análise de cluster da triangulação dos dados da pesquisa.

Figura 1 - Triangulação dos dados da pesquisa.

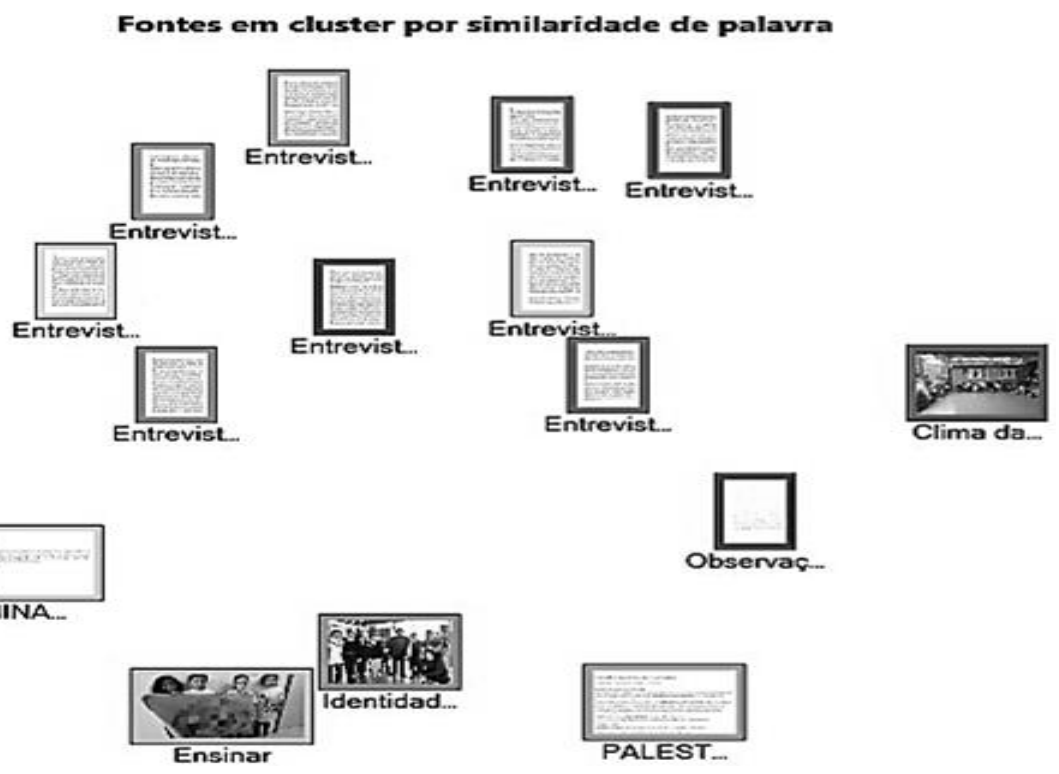

Fonte: Extraído do software NVivo®11.

Por meio da Figura 1, é possível ressaltar que todas as fontes coletadas foram conexas com o caso da ONG dentro do NVivo®, consentindo, assim, a constatação da triangulação por fontes de dados.

\subsection{ANALISE E TRATAMENTOS DOS DADOS}

Os dados coletados foram analisados por meio da técnica de análise de conteúdo, que, segundo Minayo (2017), desdobra-se nas seguintes etapas: pré-análise; exploração do material 
ou codificação e tratamento; e interpretação dos resultados. Neste contexto, Denzin et al. (2008) revelam que essa técnica busca compreender criticamente o aberto oculto das comunicações, que pode ser analisado por meio de gestos, figuras, documentos e mensagens verbais adquiridas mediante as técnicas de coletas de dados.

Depois de efetivada as entrevistas a posteriori que situam o corpus de análise, será feita a categorização, ou seja, a classificação de dados obrigatórios de um conjunto por distinção, sendo estes reagrupados em seguida de acordo com a codificação. Estes reagrupamentos ocorrem de acordo com as particularidades que são comuns a estes elementos (BARDIN, 2009).

\section{APRESENTAÇÃO E ANÁLISE DOS RESULTADOS}

As entrevistas foram transcritas e, após, foi realizada a análise de conteúdo de cada entrevista, no intuito de encontrar as categorias de análise para alcançar o objetivo do estudo (BARDIN, 2009). Este estudo enquadra-se no nível exploratório, assim foi trabalhado somente com as categorias a posteriori. Dessa forma, por meio da análise, surgiram as categorias a posteriori, conforme figura 2 .

Figura 2 - Hierarquia da codificação em cada categoria

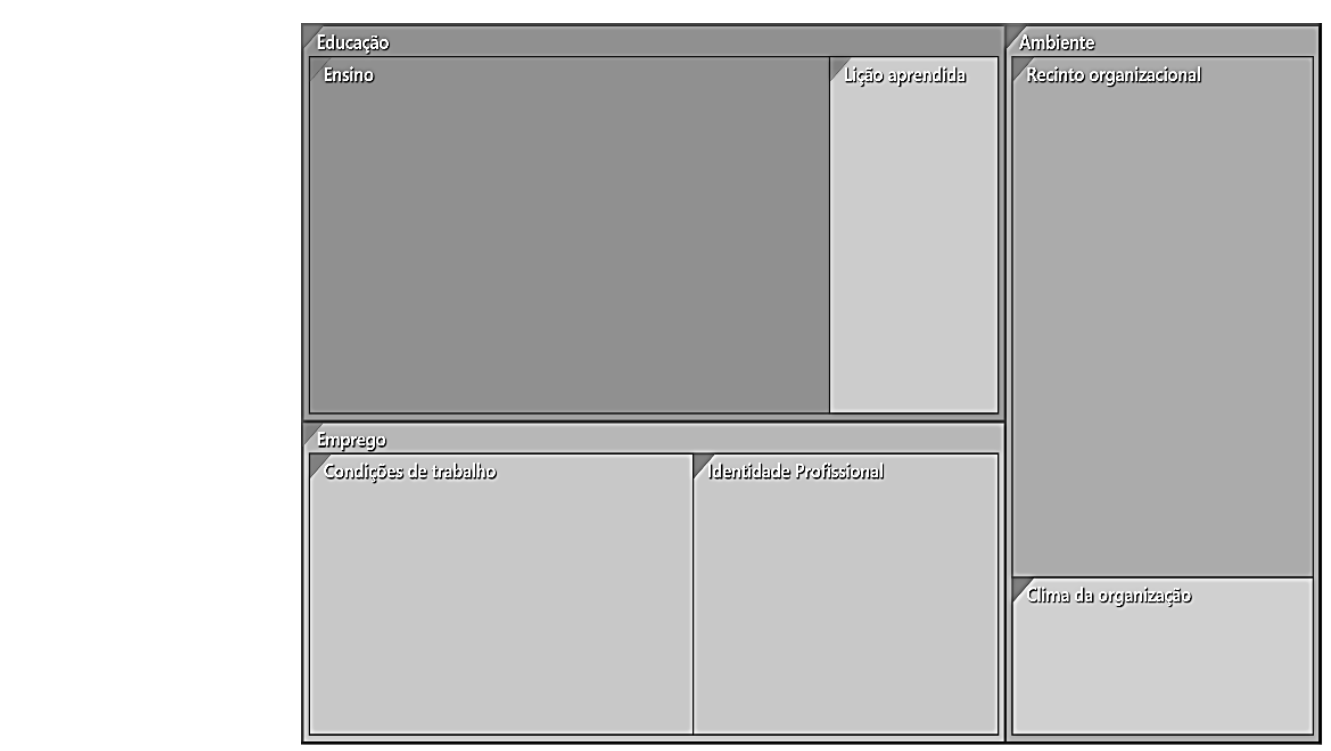

Fonte: Extraído do software NVivo®11.

Dentro do esforço deste estudo, as categorias e os processos formais e informais de aprendizagem ajuda a responder o objetivo desta pesquisa que é identificar, descrever e compreender os processos formais e informais de aprendizagem dos colaboradores de uma ONG utilizam para aprender seus afazeres profissionais. Para Flick (2016), a escrita dos 
resultados em estudos qualitativos pode ser estimada como o cerne da pesquisa social, uma vez que estabelece um utensílio para comunicar e mediar os achados e o conhecimento.

\subsection{CATEGORIA EMPREGO}

O caminho laboral dos indivíduos da pesquisa é o trajeto de sua participação profissional em organizações antes de trabalhar na casa Anjos Voluntários, e seu conhecimento é avaliado saliente para a pesquisa porque se parte do pressuposto de que o sujeito arquiteta seu próprio juízo e aprende por meio da edificação desse caminho e que não há experiência sem alguma forma de saber previamente. Dos 9 entrevistados, 2 vieram de organizações privadas e 7 trabalhavam em projetos sociais.

O ingresso na casa para atividades laborais é por meio de entrevistas e referências de trabalhos anteriores. Atualmente o E1 e o E8 trabalham só as horas de cada oficina que eles ministram (3hs), a E7, E9 trabalham meio período (20hs) e E2, E3, E4, E5, E6 trabalham período integral (40hs), as horas são computadas semanalmente.

Dentro de cada categoria foi feita uma comparação entre as subcategorias para averiguar as principais fontes de informação da categoria emprego apresentado na figura 3.

Figura 3 - Comparação das subcategorias identidade profissional e condição de trabalho.

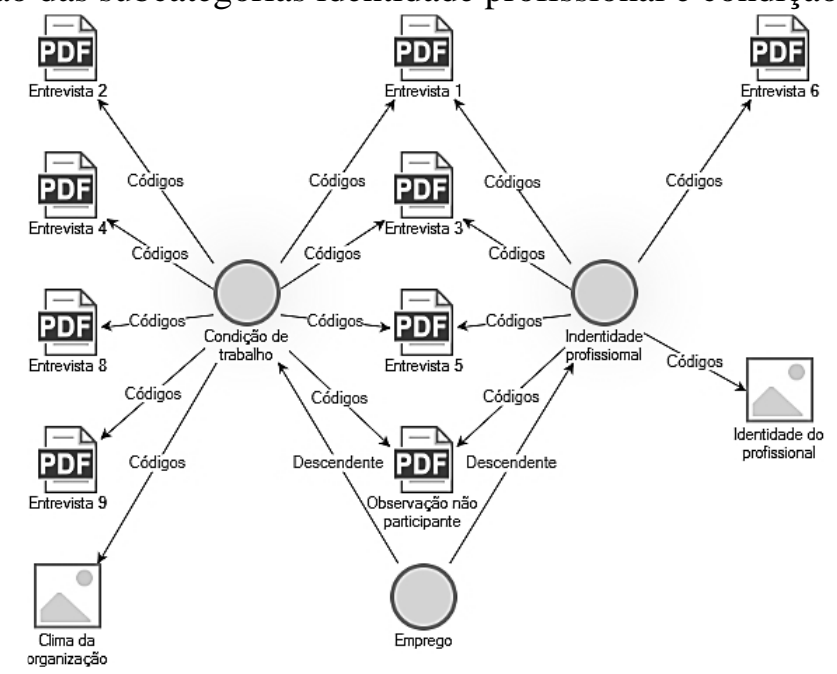

Fonte: Extraído do software NVivo®11.

Nesta categoria ficou evidente que a subcategoria, condição de trabalho apresentou 24 referencias de codificação direta e 24 agregadas, já subcategoria identidade profissional apresentou 19 referencias de codificação direta e 19 agregadas. 


\subsection{SUBCATEGORIA EMPREGO: IDENTIDADE PROFISSIONAL}

Todos os profissionais envolvidos na pesquisa são profissionais experientes sendo uma equipe multidisciplinar. Os cargos de cada entrevistado não mudam no quesito de atribuições de cargo e execução das atividades laborais, isto fica evidente que cada um dos colaboradores sabe as suas atividades, isto fica evidente na fala do E6:

[...]Como eu trabalho bem na parte da Coordenação administrativa na questão coordenação do financeiro nas questões dos projetos também captação parte burocrática e contratação de pessoal. Essas partes mais burocráticas da instituição exerço a 5 anos na instituição. Eu cuido da parte financeira quando necessita também, respondo diretamente aos diretores.

Quanto à motivação para se ingressar na $\mathrm{ONG}$, as três únicas razões foram o trabalho, ensinar - aprender e gratificação pessoal. Todos os entrevistados citaram estes termos em suas entrevistas como ratifica o E3:

[...]O trabalho é bem baseado no que eu acho assim no amor e no carinho, amor e carinho porque tudo que eles trazem para nós a gente tenta dobrar, se é carinho a gente dobrar, se é amor a gente dobra, isso é uma questão assim de ética também, a gente procura estar tentando melhorar porque em casa eles têm uma convivência no caso, eles têm um tipo de realidade e chega aqui já é outra, mas é importante lembrar que aqui eles tem uma relação muito diferente do que eles têm em casa com pai com a mãe e aqui eles têm um carinho respeito e isso é extremamente importante

Dos indivíduos ouvidos, os entrevistados, todos das áreas de suas competências de acordo com sua formação, declararam que sua formação acadêmica e/ou atividade anteriormente exercida os ajudam no trabalho dentro casa. Assim afirmado pelo E1:

[...]Sempre levantei a bandeira principalmente na área da segurança do trabalho, tudo começa pela base então se conseguimos fazer um trabalho junto desses jovens é de grande valia, claro que quando eu entrei lá não foi com essa oficina de segurança trabalho para oficina de raciocínio lógico $\mathrm{O}$ meu trabalho foi bem claro a nível do professor mesmo em sala de aula aplicando minha sistemática. Pela minha experiência de mais de 15 anos voltado à área de segurança do trabalho eu acredito que ajudou muito a principalmente aos alunos e até mesmo as pessoas que trabalham na casa que não tinha tanto conhecimento no assunto.

Os indivíduos E3 e E5, haviam trabalhado em projetos sociais na mesma área de atuação atual, afirmam que trabalharam em um outro projeto anteriormente os ajudou somente no trato com os alunos e sua aprendizagem, no entanto os procedimentos executados no dia-a-dia eram iguais. Para E8, o fato de ele trabalhar em uma outra escola e a sua formação em dança trouxe uma tranquilidade na oficina de dança para com as crianças, assim fica evidente a aprendizagem formal. A aprendizagem formal é normalmente requerida institucionalmente, por meio da sala de aula e fortemente estruturada (MARSICK; WATKINS, 1990). 


\subsection{SUBCATEGORIA EMPREGO: CONDIÇÕES DE TRABALHO}

Na subcategoria condição de trabalho os entrevistados apontam que as condições são boas e favoráveis para aprendizagem bem como para o convívio, também afirmaram que a alguns conflitos, onde se discutem assuntos pertinentes à o trabalho executado e as condições da instituição: nas áreas da assistência social, psicologia, patrocinadores e financeira. Onde se atribui os projetos e captação de recursos por meio de parcerias com empresas. A colaboração e a troca de experiências são o meio que fica evidente nesta categoria assim descrito pelos E2, E9.

[...] Eu aprendi com os educadores mais antigos, eles estavam sempre disponíveis para me ajudar então tudo que eu precisava eu observava muitos deles, e assim que eu fui aprendendo e me adaptando a casa, (E2).

[...] Pois é aqui eu aprendi, observando quem já está na casa e buscando experiências de outras pessoas prefiro a troca de experiência do que a teoria para mim é mais importante experimentar, (E9).

As colaborações por meio de processos informais de aprendizagem também foram salientadas nesta categoria e narrada pelo E5 onde ele aprendeu novas técnicas de pintura com o E3:

[...] Acabei de vir melhorando em pouco tempo com a colaboração deste profissional. Eu acho que a coisa nova que eu aprendi a pouco tempo e a questão textura de pinturas além de telas, como o E3 tem isso uma forte competência nas atividades dele, ele está nos passando um pouco disso então é uma das coisas que aprendo no momento.

A categoria condição do trabalho exposta pelo entrevistado E3 onde ele aponta que a organização da casa como instituição é bem estruturada em menção a outros projetos que o mesmo trabalhou. A E4 também apontou as condições de trabalho e a receptividade no local de trabalho:

[...] Então foi uma nova experiência para mim, para minha vida para continuar nessa caminhada com as crianças e a minha entrada então aqui na casa anjos voluntários foi tranquila, eu fui muito bem acolhida por todos os colegas.

Os indivíduos E1, E8, E3 apontam o respeito mútuo entre os colegas e a direção da casa para fortalecer a equipe e o trabalho com as crianças e as famílias. O trabalho de assistência social como encaminhamos, entrevistas, direcionamentos escolar e profissional, trabalhos focados no psicológico da criança, e o fator chave é a condição das crianças e adolescentes serem cidadãos de bem com uma formação social e profissional. 


\subsection{CATEGORIA EDUCAÇÃO}

Nesta seção, serão apresentadas as características de aprendizagem no trabalho referenciada pelos entrevistados como os facilitadores e barreiras para a aprendizagem. Para Easterby-Smith e Araújo (2001), no que tange aspecto social, a aprendizagem organizacional é um processo socialmente estabelecido pelos intercâmbios sociais que acontecem espontaneamente no ambiente de trabalho, ou seja, qual o sentido conferido pelas pessoas nos experimentos laborais. Nesta categoria foi feita uma comparação entre as subcategorias para averiguar as principais fontes de informação da categoria educação apresentado na figura 3.

Figura 4 - Comparação das subcategorias ensino e lição aprendida.

Fonte: Extraído do software NVivo®11.

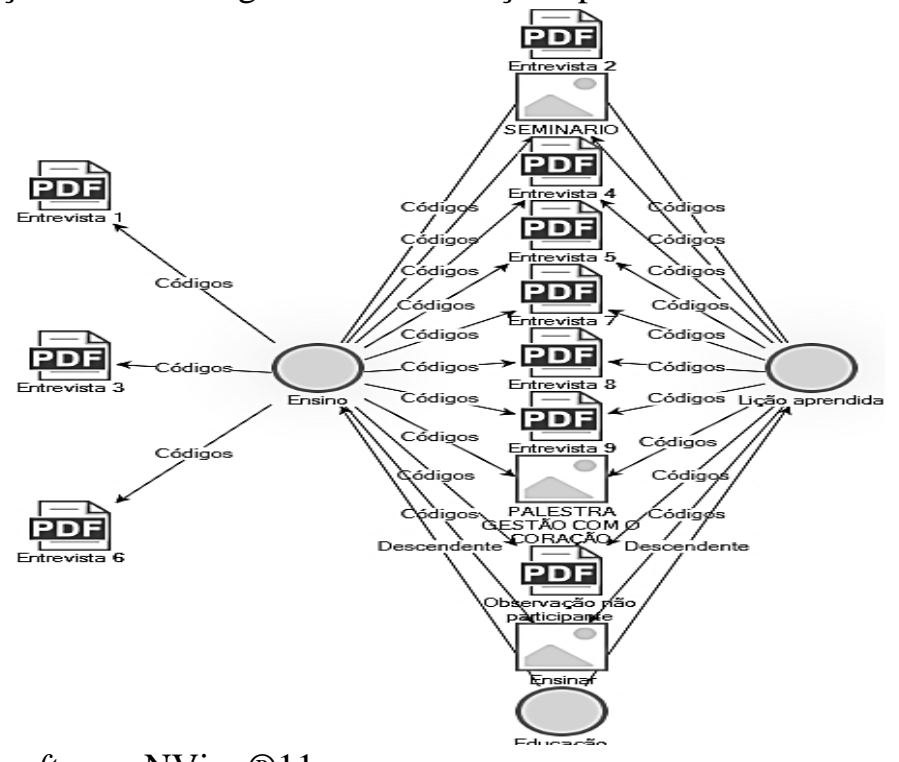

Na categoria educação ficou evidente que a subcategoria, ensino apresentou 40 referencias de codificação direta e 40 agregadas, já subcategoria lição aprendida apresentou 13 referencias de codificação direta e 13 agregadas.

\subsection{SUBCATEGORIA EDUCAÇÃO: ENSINO}

Nesta subcategoria foi abordado a questão do ensino e de como é a trajetória de aprendizagem no trabalho dos entrevistados, como aprendem coisas novas, o que foi significativo em termos de aprendizagem propriamente dito, o que foi aprendido individualmente. Segundo Antonello (2011), a aprendizagem individual constitui-se em adquirir competências, restaura-las e desenvolvê-las por meio de aprendizagem constante.

Aprendizagem relata pelos entrevistados aborda tanto a aprendizagem formal tanto quanto a informal. O E1, E4 e o E3 buscam o aprendizado por meio de leituras, cursos e 
pesquisa:

[...]Eu aprendo novas funções lendo e observando (E1). Sobre o curso que eu tive na metade de 2018 quando eu entrei foi para me atualizar mais, e ter novos conhecimentos com novas atividades no meio do serviço de convivência (E4). Eu aprendo pesquiso muito sou uma pessoa que pesquisa demais desde um rabisco que vou fazer eu vou atrás, eu pesquiso muito, tudo que eu for fazer do que me é atribuído pesquiso, vejo como vou fazer, planejo, então é dentro disso aí, procuro de várias formas como fazer (E3).

De acordo com o relato dos entrevistados E2, E5, E6, E7, E8, E9 a casa oferece cursos de aperfeiçoamento e treinamentos internos no formato formal de aprendizagem para os colaboradores, bem como cada indivíduo também busca o processo informal para aprender. Segundo Dutra (2001), a aprendizagem informal pode acontecer da aprendizagem formal, ou pela procura do entendimento, que incide por fora dos currículos representados dos cursos e dos programas educativos.

\subsection{SUBCATEGORIA EDUCAÇÃO: LIÇÃO APRENDIDA}

Neste contesto dentro da categoria educação, ficou evidente as lições isto é: lição de aprendizagem da função exercida, lição aprendida em outras experiências de trabalho, lição aprendida dos treinamentos vivenciados, lição da interação com os colegas de trabalho, este seria o objetivo da categoria lição. A visão de escopo da captura de lições aprendidas é "compartilhar e reutilizar a informação derivada da experiência em melhoramento a visões futuras" (YAP et al., 2017).

No que tange as lições aprendidas fica latente na narrativa E7 o que foi aprendido em outras reuniões:

[...]Antes do atendimento das crianças a gente faz reunião de equipe, na equipe técnica que é assistente social, psicólogo e a coordenação para discutir os casos, tem alguns casos bem complicados de vulnerabilidade e risco que a gente já passou aqui, às vezes então se discuti os casos parecidos e o que dá para adaptar nos novos casos.

As lições aprendidas também derivam dos treinamentos feito na casa assim relata pela E9:

[...]O ano passado (2018), a gente teve o projeto conhecer e daí a gente trouxe os profissionais da psicopedagogia e psicologia, é sempre é muito rico inclusive está agregando a participação de professores das escolas que os nossos alunos frequentam interessa também a troca com esses profissionais a gente vai buscar mais cursos esse ano (2019).

Desta forma a lição aprendida na visão dos E5, E2, E4 e E8 vem do trabalho da equipe e das conversas informais conversando sobre cada uma das crianças e adolescentes o seu histórico familiar, educacional, saúde e convívio social isto é onde está criança ou adolescente está inserido no mundo. 


\subsection{CATEGORIA AMBIENTE}

O que diz respeito a categoria ambiente foi analisada três situações que foi abordada por todos os entrevistados: cultura interna de cooperar com as crianças e adolescentes bem como as famílias, clima organizacional no que se refere ao convívio e ambiente de aprendizagem cultural. Um estudo de Marsick e Watkins (2003) desenvolveram o instrumento chamado DLOQ - "the Dimensions of the Learning Organizations Questionnaire". Ele avalia clima, cultura, sistemas e estruturas que influenciam como os indivíduos aprendem.

Figura 4 - Comparação das subcategorias clima da organização e recinto organizacional.

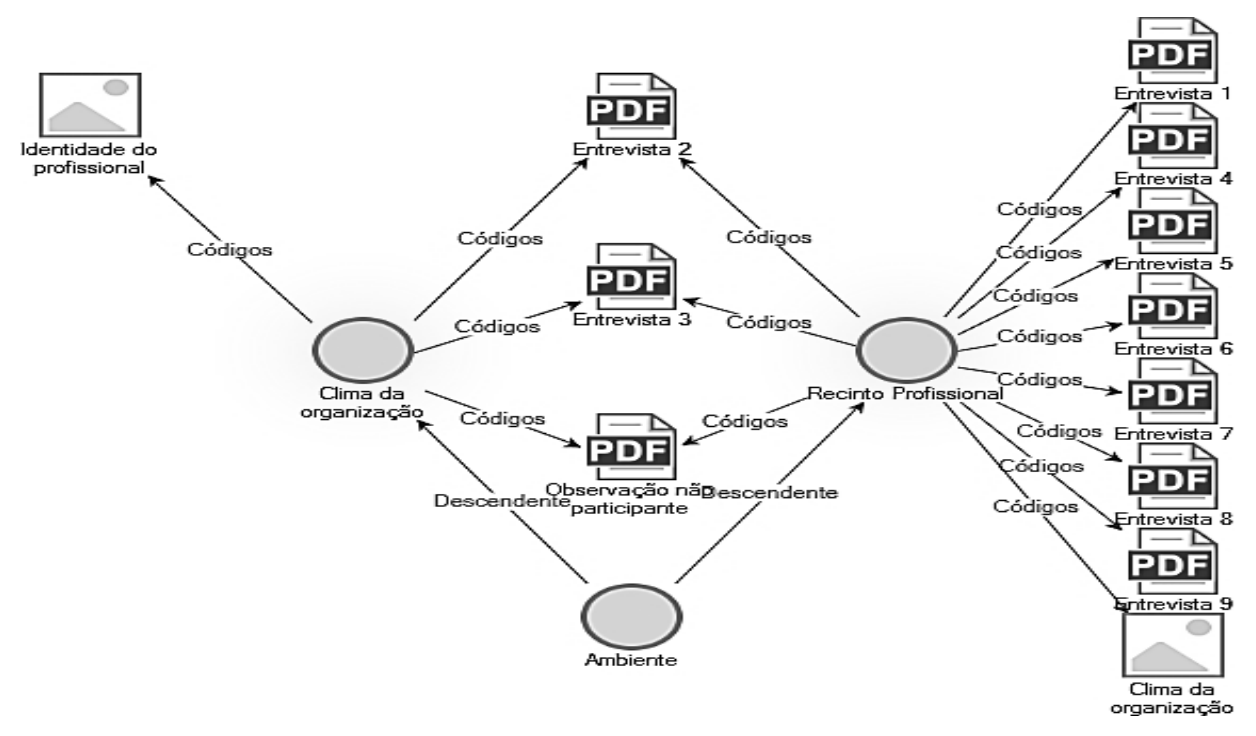

Fonte: Extraído do software NVivo®11.

$\mathrm{Na}$ categoria ambiente ficou evidente que a subcategoria, recinto organizacional apresentou 33 referencias de codificação direta e 33 agregadas, já subcategoria clima da organização apresentou 10 referencias de codificação direta e 10 agregadas.

\subsection{SUBCATEGORIA AMBIENTE: CLIMA DA ORGANIZAÇÃO}

O clima organizacional organização também foi apontado pelos entrevistados onde dica em evidencias a cooperação na aprendizagem e o respeito entre os colaboradores. No que culmina a questão das crianças e adolescentes o clima de trabalho é favorável ao aprendizado social. No caso dos educadores sociais que oferecem aprendizagens como: pintura e jogos para as crianças elas já saem com uma boa formação. De acordo com Martins, Picosque e Guerra (1998) ainda destacam que é do entusiasmo do educador que nasce o brilho dos olhos dos aprendizes. Brilho que ajuíza ao mesmo tempo o olhar do mestre. 
A entrevistada E2 aborda na sua narrativa a questão da cooperação mutua na casa e de como é este ambiente:

[...] Eu trabalho em conjunto com os outros educadores, a gente nunca trabalhou sozinho aqui, sempre cooperando, a equipe é muito boa. Eu acho que é aqui na casa é bom trabalhar porque todo mundo tem a sua função, mas se precisar todo mundo ajuda todo mundo.

O entrevistado E3 salienta a questão também de que a casa é um ambiente de respeito e carinho para as crianças:

[...] Convivência com os colegas e a convivência com os alunos é de respeito e carinho é questão de estudo e o que fica é lembrança até hoje de alunos aí com 20 anos que a gente encontra, conversa, eu acho que fica isso como convivência e do fortalecimento do vínculo familiar.

No estudo de Shein (1994) ele aborda algumas dimensões onde a orientação para as pessoas, a crença compartilhada de que as pessoas podem e almejam aprender, valorização da aprendizagem e da mudança, tempo disponível para inovação e experimentação, trabalho em grupo, consciência de uma interdependência no trabalho ficam evidente nesta subcategoria.

\subsection{SUBCATEGORIA AMBIENTE: RECINTO ORGANIZACIONAL}

A subcategoria recinto organizacional está constituída do ambiente tangível e intangível do trabalho na casa, bem como as expectativas e receios do futuro da organização. Neste caso não é feita uma análise de macroambiente ou microambiente e sua importância, mas sim a percepção dos entrevistados sobre a organização que eles trabalham. Segundo Hitt, Ireland e Hoskisson (2008), por sua vez, não conferem maior ou menor valor ao macro ou ao microambiente organizacional. Pelo oposto, resguardam a combinação dos diagnósticos desses ambientes que, na visão deles, pode aperfeiçoar a performance da organização que agrega os insights providos por essas análises.

Os entrevistados E1, E2, E3, E4, E6 e E8 relatam que o ambiente é excelente para se trabalhar:

[...]É perfeito é muito família muita dedicação por parte de todos (E1). O ambiente ele é bom, mas poderia ser bem maior que eu acho que o espaço poderia abranger mais crianças, mas o ambiente assim é bem tranquilo (E2). Eu acho o ambiente bom de trabalhar bacana traz bastante benefício para todos tem uma boa grade de oficina que é ótimo traz um calendário de atividades, que é importante para desenvolvimento das crianças e também para saúde mental dos educadores e professores de oficinas (E3). Então um ambiente excelente aqui em todos os aspectos lugar os colegas (E4). Ambiente excelente a gente tenta mudar sempre para melhor, o bom deste lugar falando em ambiente de trabalho é o convívio embora nosso ambiente físico também seja pequeno (E6). Eu acho bem conveniente e bom, adequado para a atividade que eu que eu exerço (E8) 
Outros entrevistados como E9 e E7 afirma que a questão do ambiente poderia ser ais formal nas questões de seguir alguns protocolos internos na organização:

[...]Acho que a casa precisa absorver um pouco mais dessa formalidade e acho que ela ajudará bastante inclusive no clima entre as pessoas e na comunicação das pessoas porque senão se perde um pouco controle das coisas (E9). A gente tem que estar sempre lembrando do teu código de ética das suas atribuições do que é ser assistente social porque tu está aqui fazendo valer os direitos das crianças e adolescentes e não para fazer qualquer tipo de pré-julgamento (E7).

O interessante que a casa Anjos Voluntario é uma ONG e necessita de seguir também protocolos ter uma estrutura organizacional consolidada. Souza (2004), aborda que é indispensável a compreensão de aspectos como estruturas organizacionais, políticas de gestão de pessoas, cultura, valores, tipos de liderança, competências, entre outros, que podem beneficiar ou atrapalhar os processos da aprendizagem organizacional (DABBAGH; KITSANTAS, 2012; RACKUS et al., 2019).

\section{DISCUSSÃO DOS RESULTADOS}

Nesta etapa da usamos uma análise de cluster de frequência de palavras para evidenciar os principais termos que evidenciam está pesquisa. A figura 5 apresenta a frequência dos principais termos desta pesquisa.

Figura 5 - Mapa de frequência de palavras derivadas da pesquisa.

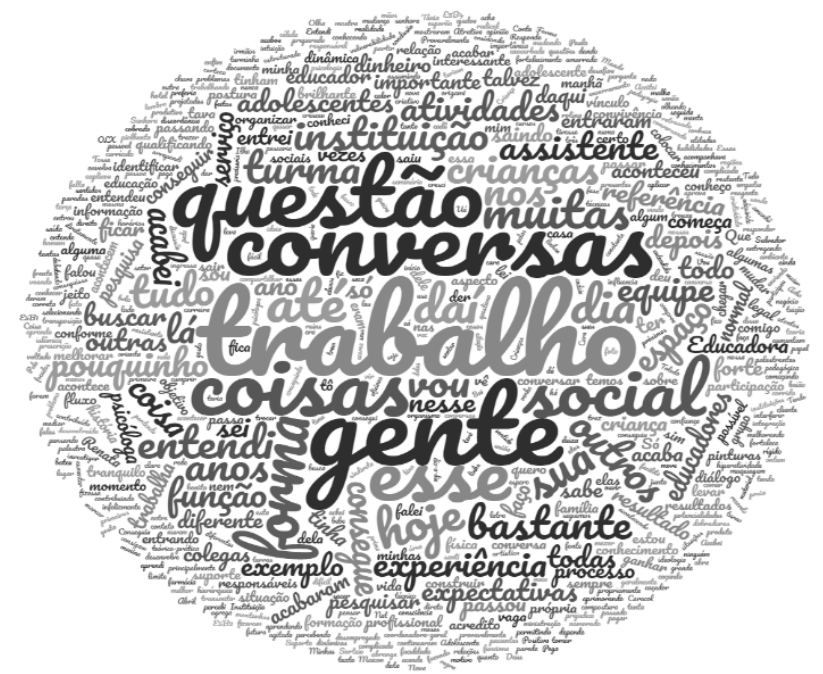

Fonte: Extraído do software NVivo®11

A palavra trabalho apareceu 145 vezes, a palavra gente 49 vezes, a palavra conversa 14 vezes, a palavra questão 12 vezes e por último a palavra coisas 11 vezes. A palavra trabalho aponta o objeto de pesquisa e a palavra conversas denota a aprendizagem no ambiente de trabalho. (MARSICK; YATES, 2012; SOUZA, 2004; DUTRA, 2001). Para uma síntese mais 
apurada foi possível chegar a uma figura conceito deste estudo: A figura 6 apresenta as relações das categorias e a aprendizagem forma e informal deste estudo.

Figura 6 - Relações das categorias e a aprendizagem forma e informal deste estudo.

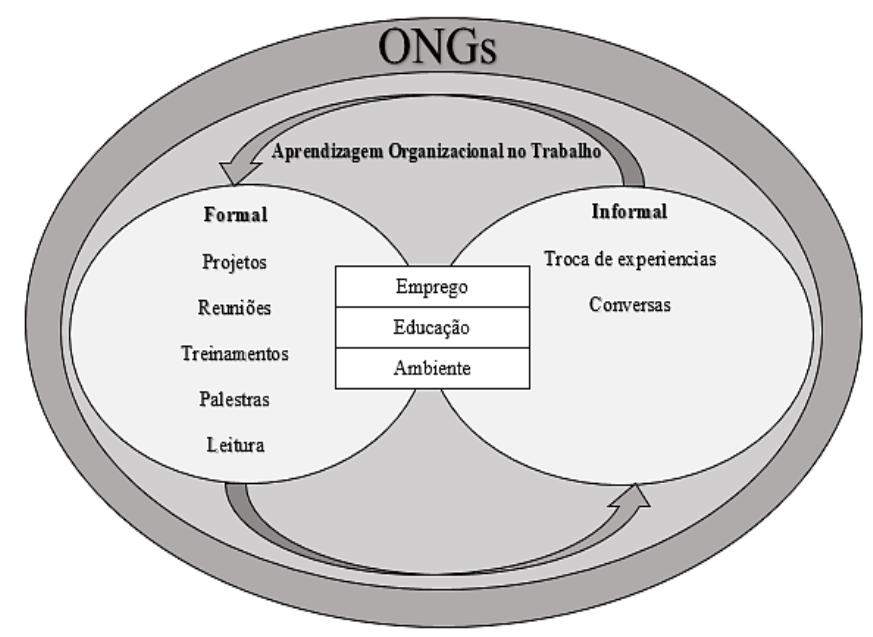

Fonte: elaborado pelos autores. (2019).

Seguindo o raciocínio da figura conceito deste estudo a categoria apresentada a relação com os processos de aprendizagem formal e informal na ONG, a categoria emprego tem relação com as trocas de experiências e conversas que no caso é uma aprendizagem informal com reuniões, projetos, treinamentos, palestras e leitura que no caso é são aprendizagem formal (PETERS; ROMERO, 2019). A categoria educação tem relação com treinamentos, projetos, palestras e leituras e que é um método formal de aprendizagem, mas se não houver uma troca de conversas que é um método de aprendizagem informal não haveria aprendizagem (ANTONELLO, 2011). A categoria ambiente o ambiente de palestras, treinamentos, leitura, reuniões e projeto é uma forma de aprendizagem formal, logo então a necessidades de troca de experiências e conversas que é uma aprendizagem informal (YAP et al., 2017).

As categorias do estudo funcionam como um elo entre a aprendizagem formal e informal em organizações não governamentais formando um ciclo de aprendizagem representados pelas setas e as interações de trocas de experiências tanto na aprendizagem forma e na informal complementam este ciclo em concordância com o raciocínio desenvolvido pelos autores Antonello e Godoy $(2009,2010)$ que apontam trocas de experiências práticas e vivenciadas nas organizações levam a aprendizagem (DABBAGH; KITSANTAS, 2012). 
INOVAÇÃO

\section{CONSIDERAÇÕES FINAIS}

Ao realizar esta pesquisa sobre a aprendizagem formal e informal em uma ONG, percebeu-se a importância dos treinamentos formais e principalmente as trocas informais que ocorrem no cotidiano dos colaboradores da casa. Estes colaboradores a aprendem sobretudo tendo a troca de experiência em seu cotidiano e quanto mais aprendem, mais se ponderam sobre o seu aprendizado.

Abranger como a aprendizagem acontece no ambiente de trabalho pode ajudar e estabelecer inovações para apoiar os processos de aprendizagem. Com isto proporciona a probabilidade de adentrar novas unidades de análise como as ONGs, seus os processos de grupos ou de comunidades de prática. A experiência praticas dos colaboradores da ONG é o fato gerador da aprendizagem dentro desta organização. Um raciocínio compartilhado pelos autores Antonello e Godoy $(2009$, 2010) apontam que o subsídio da aprendizagem poderá vir da adoção da corrente de pensamento da aprendizagem fundamentada na prática (RACKUS et al., 2019).

Em meio as formas de aprendizado informal, constituíram identificadas as trocas com os colaboradores por meio de outra experiência em outros projetos em conversas de permutas de informação e experiências decorridas de trabalhos anteriores. (PETERS; ROMERO, 2019). Quanto às formas de aprendizagem formal, acontecem na forma de leitura, treinamentos, reuniões, palestras e projetos. Um fator positivista que o estudo apontou que tanto nos processos formais e informais o aprendizado na organização também se dá na forma de cooperação entre os setores e colaboradores. E em concordância com os autores Antonello e Godoy (2010) a aprendizagem é abrangida pelo emergir de afinidades e interações das pessoas com os elementos sociais e materiais de conjuntos privados. A referentes entraves da pesquisa poderia se ter abordado mais respondentes pois a ONG conta com 10 professores de oficina foram entrevistados somente 2. Em questão limitação do método qualitativo poderia se ter feito um estudo de caso para dar profundidade a o assunto ou estudo múltiplos casos para se fazer comparações entre os casos. Para pesquisas futuras poderia ser abordado um estudo de caso múltiplo no tema do referente estudo, ou até mesmo uma etnografia. 


\section{REFERÊNCIAS}

ABAAD, G.; BORGES-ANDRADE, J. Aprendizagem humana nas organizações e trabalho. In: ZANELLI, J. C.; BORGES-ANDRADE, J. E.; BASTOS, A. V. B. (orgs.). Psicologia, organizações e trabalho no Brasil. Porto Alegre: Artmed, 2004. p. 237-275.

ANESE, V.; COSTA, C.; COELHO, E. A. Impacto social das ações em uma organização sem fins lucrativos. Revista pensamento contemporâneo em administração, Niteroi, v. 12, n. 1, p. $61-75,2018$

ANTONELLO, C. S. Saberes no singular? Em discussão a falsa fronteira entre Aprendizagem Formal e Informal. In: ANTONELLO, C. S.; GODOY, A. S. (orgs.) Aprendizagem organizacional no Brasil. Porto Alegre: Bookman, 2011. p. 225-245.

ANTONELLO, C. S.; GODOY, A. S. A encruzilhada da aprendizagem organizacional: uma visão paradigmática. Revista de Administração Contemporânea, Maringá, v. 14, n. 2, p. 310-332, 2010.

ANTONELLO, C. S.; GODOY, A. S. Uma agenda brasileira para os estudos em aprendizagem organizacional. Revista de Administração de Empresas, Rio de Janeiro, v. 49, n. 3, p. 266-281, 2009.

ARGYRIS, C.; SCHON, D. A. Organizational learning II: theory, method and practice. New York: Addison-Wesley, 1996.

ASSOCIAÇÃO BRASILEIRA DE ORGANIZAÇÕES NÃO-GOVERNAMENTAIS (ABONG). O que é uma ONG? São Paulo: Abong, [2020?]. Disponível em: www.abong.org.br. Acesso em: 4 fev. 2019.

BARDIN, L. Análise de conteúdo. 4. ed. Paris: PUF, 2009

BEDNALL, T.C.; SANDERS, K. D. Opportunities for Formal Learning Stimulate Follow-Up Participation in Informal Learning? A Three-Wave Study. Human Resource Management, [s. 1.], v. 56, n. 5, p. 803-820, 2017.

BORGES-ANDRADE, J. E.; ABBAD, G. dá S.; MOURÃO, L (orgs.). Treinamento, desenvolvimento e educação em organizações e trabalho: fundamentos para a gestão de pessoas. Porto Alegre: Bookman, 2006

BOUD, D.; GARRICK, J. Understandings of workplace learning. In: GARRICK, J. Informal Learning in the Workplace: Unmasking Human Resource Development. London: Routledge, 1998. p. 1-11.

BRANDI, U.; ELKJAER, B. Organizational Learning Viewed from a Social Learning Perspective. In: EASTERBY-SMITH, M.; LYES, M. A. Handbook of Organizational Learning and Knowledge Management. New York City: Wiley Publication, 2011. p. 23-38

DABBAGH, N.; KITSANTAS, A. Personal Learning Environments, social media, and selfregulated learning: A natural formula for connecting formal and informal learning. The Internet and Higher Education, [s. 1.], n. 15, v. 1, p. 3-8. 2012. 
DENZIN, N. K.; LINCOLN, N, Y. S. Collecting and interpreting qualitative materials. 3. ed. Thousand Oaks, Calif: Sage, 2008. Disponível em:

https://us.sagepub.com/enus/sam/collecting-and-interpreting-qualitativematerials/book237870. Acesso em: 10 jan. 2019.

DUTRA, J. S. (Org). Gestão por competências. São Paulo: Gente, 2001.

EASTERBY-SMITH, M.; ARAÚJO, L. Aprendizagem Organizacional: Oportunidades e Debates Atuais. In: EASTERBY-SMITH, M.; BURGOYNE, J; ARAÚJO, L. (coords.) Aprendizagem Organizacional e Organização de Aprendizagem: Desenvolvimento na Teoria e na Prática. São Paulo: Atlas, 2001. p. 15-38.

FLICK, U. Challenges for a New Critical Qualitative Inquiry: Introduction to the Special Issue. Qualitative Inquiry, [s. 1.], v. 23, n. 1, p. 3-7, 2016

FLICK, U. Desenho da Pesquisa Qualitativa. Porto Alegre: Bookman Artmed, 2009.

GODOY, A. S. Refletindo sobre Critérios de Qualidade da Pesquisa Qualitativa. Revista Eletrônica de Gestão Organizacional, Recife, v. 3, n. 2, p. 86-94, 2005.

GUERRA, M. T. T; MARTINS, C. F. D; PICOSQUE, G. Didática do Ensino da Arte: A língua do mundo, poetizar, fruir e conhecer arte. São Paulo: FTD, 1998.

HITT, M. A.; IRELAND, R. D.; HORKISSON, R. E. Administração estratégica: competitividade e globalização. 2. ed. São Paulo: Thomson Learning, 2008.

MALCOM, J.; HODKISON, P.; COLLEY, H. The interrelationships between informal and formal learning. Journal of Workplace Learning, [s. 1.], v. 15, n. 7/8, p. 313-318, 2003.

MARCH, J. Exploration and exploitation in organizational learning. In: COHEN, M.; SPROLL, L. Organizational Learning. California: Sage, 1995.

MARSICK, V. J., WATKINS, K. E. Informal and Incidental Learning. New Directions for Adult and Continuing Education, [s. 1.], v. 89, p. 25-34, 2001.

MARSICK, V. J.; WATKINS, K. E. Demonstrating the Value of an Organization's Learning Culture: The Dimensions of the Learning Organization Questionnaire. Advances in.

Developing Human Resources, [s. 1.], v. 5, n. 2, p. 132-151, 2003.

MARSICK, V. J.; WATKINS, K. Informal and incidental learning in theworkplace. London: Routledge, 1990.

MARSICK. J.; YATES, J. L. Informal Learning and Complex Problem Solving of Radiologic Technologists Transitioning to the Workplace. In: HOU, H. New Research on Knowledge Management Applications and Lesson Learned. Croatia: InTech, 2012. p. 171-194.

MINAYO, M. C. de S. Scientificity, generalization and dissemination of qualitative studies. Ciência e saúde coletiva, Rio de Janeiro, v. 22, n. 1, p. 16-17, 2017.

PETERS, M.; ROMERO, M. Lifelong learning ecologies in online higher education: Students' engagement in the continuum between formal and informal learning. British Journal of Educational Technology, London, v. 50, n. 4, p. 1729-1743, 2019. 
RACKUS, D. G. et al. Learning on a chip: Microfluídicos para educação científica formal e informal. Biomicrofluidics, [s. 1.], n. 13, v. 4, 2019.

REATTO, D. Os processos de Aprendizagem Informal no local de trabalho: um estudo com técnicos-administrativos numa faculdade pública estadual. Dissertação (Mestrado em Administração de Empresas). Universidade Presbiteriana Mackenzie, São Paulo, 2014.

REATTO, D; GODOY, A. S. A produção sobre Aprendizagem Informal nas organizações no Brasil: mapeando o terreno e rastreando possibilidades futuras. Revista Eletrônica de Administração, Porto Alegre, v. 21, n. 1, p. 57-88, 2015.

RIBEIRO, A. M. V.; LUZ, T. R. O sentido do trabalho para trabalhadores de organizações não governamentais. In: HELAL, D. H.; GARCIA, F. C.; HONÓRIO, L. C. (orgs.). Relações de poder e trabalho no Brasil contemporâneo. Curitiba: Juruá, 2010. p. 75-107.

SCHEIN, E. Organizational and managerial culture as a facilitator or inhibitor of organizational learning. MIT Sloan School of Management, may.1994.

SHIRIVASTAVA, P. A typology of organizational learning systems. Journal of Management Studies, [s. 1.], v. 20, n. 1, 1983.

SOUR, R. H. Poder cultura e ética nas organizações. Rio de Janeiro: Campus, 1999.

SOUZA, Y. S. Organizações de aprendizagem ou aprendizagem organizacional. RAE eletrônica, São Paulo, v. 3, n. 1, 2004.

STAKE, R. E. The art of case study research. Thousand Oaks: Sage, 1995.

TOURÉ, C.; MICHEL, C.; MARTY, J.C. How to promote informal learning in the workplace? The need for incremental design methods. Anals. Porto, Portugal: International Conference on Computer Supported Education, 2017.

YAP, J. B. H. et al. Collaborative model: Managing design changes with reusable project experiences through project learning and e ffective communication. International Journal of Project Management [s. 1.], p. 1253-1271, 2017.

YIN, R. K. Estudo de caso: planejamento e métodos. 4. dd. Porto Alegre: Bookman, 2010. 